\title{
Populational Fluctuation and Distribution of Epitrix spp. Foudras (Coleoptera: Chrysomelidae) in the Organic Tobacco Management in Santa Cruz do Sul, RS, Brazil
}

\author{
Daiana Oliveira1, Kássia Cristina Freire Zilch², Fabiele Cristine Hintz¹, Andreas Köhler1 \\ ${ }^{1}$ Laboratory of Entomology, Universityof Santa Cruz do Sul-UNISC, Santa Cruz do Sul, Brasil \\ ${ }^{2}$ Laboratory of Biological Control of Insects, Phytosanitary Department, Federal University of Rio Grande do Sul-UFRGS, \\ Porto Alegre, Brasil \\ Email: daiana_oliveirabio@hotmmail.com, fabielle63@hotmail.com, andreas@unisc.br, \\ kassiazilch@gmail.com
}

How to cite this paper: Oliveira, D., Zilch, K.C.F., Hintz, F.C. and Köhler, A. (2017) Populational Fluctuation and Distribution of Epitrix spp. Foudras (Coleoptera: Chrysomelidae) in the Organic Tobacco Management in Santa Cruz do Sul, RS, Brazil. American Journal of Plant Sciences, 8, 3285-3294.

https://doi.org/10.4236/ajps.2017.812221

Received: September 28, 2017

Accepted: November 27, 2017

Published: November 30, 2017

Copyright $\odot 2017$ by authors and Scientific Research Publishing Inc. This work is licensed under the Creative Commons Attribution International License (CC BY 4.0).

http://creativecommons.org/licenses/by/4.0/ (c) $\underset{\mathrm{EY}}{\text { (i) Open Access }}$

\begin{abstract}
Among the chrysomelids, some species are considered agricultural pests, such as some representatives of Epitrix spp. Popularly known as tobacco flea, these beetles cause damage to tobacco (Nicotiana tabacum L.) by feeding on the leaf surface, causing injuries, reducing productivity and the final quality of the product to be marketed. However, studies of the biology and interactions of these individuals with the environment become essential in order to develop effective and sustainable control measures. The objective of this study was to analyze the distribution and population fluctuation of Epitrix spp., as well as to evaluate the possible influence of temperature, rainfall and adjacent vegetation on the population dynamics of this beetle in organic tobacco growing in the municipality of Santa Cruz of the South, RS. The collections were carried out weekly during the 2011/2012 harvest, using Malaise and Pit-fall traps, distributed in four points along three lines. A total of 1584 individuals belonging to the genus Epitrix were collected, and their greatest abundance was observed in late January and early February 2012 due to climatic factors, such as rainfall and temperature, favorable to the development of specimens and the tobacco leaf harvesting reduced the availability of food and conditioned a greater movement of these individuals in the crop. The results presented here are of great importance for deciding the best methodology for controlling the smoke flea, as well as knowing the influence of abiotic factors on the behavior of these organisms in the field.
\end{abstract}




\section{Keywords}

Tobacco Flea, Insect Pests, Phytophagous, Nicotiana tabacum

\section{Introduction}

Epitrix spp. Foudras, 1859 (Chrysomelidae, Galerucinae) are commonly known as "flea beetles", due to their modified hind femora, which gives to this species an outstanding jumping ability. They are small phytophagous bugs, with a range of 1.5 to $3.0 \mathrm{~mm}$. The genus is cosmopolitan, comprising about 180 known species. However, the Neotropical region is responsible for the greatest diversity indexes [1] [2] [3].

As being cryptical species that show very specific morphological patterns between them, the flea beetles are common mentioned in several studies as Epitrix spp. In the case of tobacco (Nicotiana tabacum L.) cropping fields, the most common species is Epitrix fasciata Blatchey [4].

Tobacco flea is known as a late pest in planting tobacco, once they attack the crops when the plants reach their greatest growth, at the final of the productive cycle. It moves flying in search of food, and it is observed a greater movement of these specimens after the harvest of the lower leaves of the tobacco, resulting in high numbers of individuals collected in this period.

Epitrix spp. among several others Chrysomelidae groups, are one of the most remarkable tobacco plagues in the Brazilian Southern region [5]. According to Altieri [6], the emergence of these pests, as well as related phytosanitary problems are associated with the structural simplification of habitat, since wild vegetation is replaced by a monoculture.

The main food sources of Epitrix are the Solanaceae plants. However, they are able to eat other botanic families, as Chenopodiaceae, Cucurbitaceae and Fabaceae, in the case of unavailability of their main host [3]. This group is considered a plague, considering that their life phases are able to attack different parts of the host plants, therefore being responsible to a series of damages. Specifically, the adults feed the "airborne part" of the host, causing several injuries to the young plants, causing small rounded holes, making them deformed and reducing the photosynthetic area, weight and quality of plants. The females oviposit at the base of the stalk, and the larvae develop in the soil, feeding with roots and tubercules, causing damages and allowing the attack of microorganisms [2] [5].

There are several tobacco species, all of them American natives, but Nicotiana tabacum is known as the most cultivates, with all its leaves used in commercial production of cigarettes. $N$. tabacum is a solanacea with medium height of 90 to $150 \mathrm{~cm}$, according to their variety [7]. The Southern Region of Brazil is responsible for the greatest amount of cropped area of this country, with approximated 155,100 hectares in 2013-2014 seasons, with a final production of 247,410 ton [8] [9]. This is a very important crop in economic terms, as it presents a very prof- 
itable commercial value, as well the capacity of generating jobs in several sectors, from the cropping to the manufacturing of the final products [10].

Biodiversity is of the utmost importance in crop defenses. The more diverse the plants, animals and soil organisms that occupy an agricultural system, the greater the diversity of natural enemies of pests that the production unit can sustain [11]. The maintenance of vegetal diversity, both within cultivated and adjacent areas, stimulates growth of some natural enemies populations [12].

The tobacco cropping demands a great utilization of synthetic products for its maintenance, causing environmental impacts and health damages to the farmers. Considering this, more substantial researches, as well as effective actions that are able to reduce the environmental impacts of croppings, like this without a production affect, assume great importance and urgency. In this case, it is possible to mention some integrated pest management and, studies about the biodiversity and its trophic relations inside the croppings.

The literature related to Epitrix in tobacco cultivation is scarce in Brazil. There is more recent research on population fluctuation and spatial distribution of Diabrotica speciosa Gemar, 1824 on organic tobacco cultivation [13].

Considering these facts, the aim of this study is analyze the distribution and populational fluctuation of Epitrix spp., as well as evaluate possible influences by temperature, pluviosity and adjacent vegetation in the population dynamics of the species in cultivation of organic tobacco at Santa Cruz do Sul, Rio Grande do Sul, Brazil.

\section{Material and Methods}

The research was conducted in Virginia-type tobacco cropping, with an organic management, at the Worldwide Center for Agronomic Development, Extension and Training (ADET), a property of Japan Tobacco International (JTI) located at the Industrial District of the municipality of Santa Cruz do Sul, Rio Grande do Sul, Brazil. The adopted management is annually inspected and certified by CEE 2092/91 (European Union) and USA NOP - 7 CFR Part 205 (USA National Organic Program).

Santa Cruz do Sul $\left(29^{\circ} 43^{\prime} 59^{\prime \prime}\right.$, $\left.52^{\circ} 24^{\prime} 52^{\prime \prime W}\right)$, in the State of Rio Grande do Sul, Brazil, is a city that abranges an area of $733.5 \mathrm{~km}^{2}$. It is located in the Centro Oriental Riograndense mesorregion, as well as the geomorphological complex of Periferic Sul-Riograndense Depression, in a low altitudes belt, with no more than $150 \mathrm{~m}$. The climate is Subtropical. The medium temperature is $20.1^{\circ} \mathrm{C}$, with the high of $26.4^{\circ} \mathrm{C}$ and minimum of $13.8^{\circ} \mathrm{C}$. About the annual precipitations, occur in a period of 91 - 153 days, with variation between 858.8 and $2.325 .4 \mathrm{~mm}$ [14] [15] [16] [17].

Spatial distributions and population fluctuations of Epitrix spp. were analyzed due to an analysis of weekly samplings collected in the tobacco cropping fields, in a total of 14 collects that were made during the period November 2011 March 2012, about four weeks after the last crop collecting. 
Three sampling transects were placed next to the cultivation fields (Line 01, Line 02 and Line 03), chosen because they covered three different "phytophysiognomies" which could influence the population dynamics of Epitrix spp. In the first line, there was a forest of Eucalyptus spp along with medium and large shrubs. The edge of Line 02 was a forest with species of native trees, with smaller height. The vegetation adjacent to Line 03 was composed by grasses. These transects were separated by a distance of $20 \mathrm{~m}$ and the distribution of the sampling points was according to a gradient outside the center of the field.

The lines were divided into four sampling points (Outside, Border, Inside and Center), with at least eight meters of distance between them. At each point, were disposed four Pit-fall traps and a Malaise trap.

The identification and quantification of the collected specimens were realized at Laboratory of entomology of Santa Cruz do Sul, with stereoscope microscope and based on the taxonomic key of Rafael et al. [18], in the first moment at taxonomic levels of order and family. More specifically, keys like Bryant [19], Costa Lima [20] and Bechyné [21] were used to a general identification. The collected material was deposited in the entomological collection of Santa Cruz do Sul (CESC), and preserved in ethanol 70\%.

To have a better observation of the spatial distribution and populational fluctuation of Epitrix spp. in the study fields, tridimensional maps were plotted by ArqView. In case of the evaluation of temperature and pluviosity patterns and its influence on populational dynamics of Epitrix in the tobacco fields, meteorological data collected at the nearest station and powered by INMET, in the municipality of Rio Pardo, about $26 \mathrm{~km}$ of Santa Cruz do Sul, were used.

About the data analysis, the obtained results were submitted to Kruskal-Wallis' index for variance, and the mediums were compared by Dunn's test for non-parametric data. The significance level considered in this study was $\alpha=$ 0.05. A Pearson's correlation test was also conducted. The data were statistically compared in softwares like BioEstat 5.0 and PAST v 2.17 [22] [23].

\section{Results and Discussion}

Associated with tobacco cultivation, 1584 individuals of Epitrix spp. were sampled, with $86.57 \%$ collected in Malaise traps and the others $13.43 \%$ in Pit-fall. The most abundant period was between the end of January and beginning of February of 2012, with $78.4 \%$ of the total sampling (Figure 1). This is the period when the tobacco leaves are well developed, granting a great feeding source for plagues.

Before this period, the collection of the first lower tobacco leaves is normally made. Considering this, there is a possibility of greater movement by the adult flea beetles, caused by the initial scarcity of sources (Table 1). Costa-Lima [20] mentions that the lifecycle of Epitrix is, approximately, a month and a half. This inference was observed in this study, when the concentration of incidences of Epitrix occurred in a period of six weeks. 


\section{$\mathbf{N}^{0}$ Ind.}

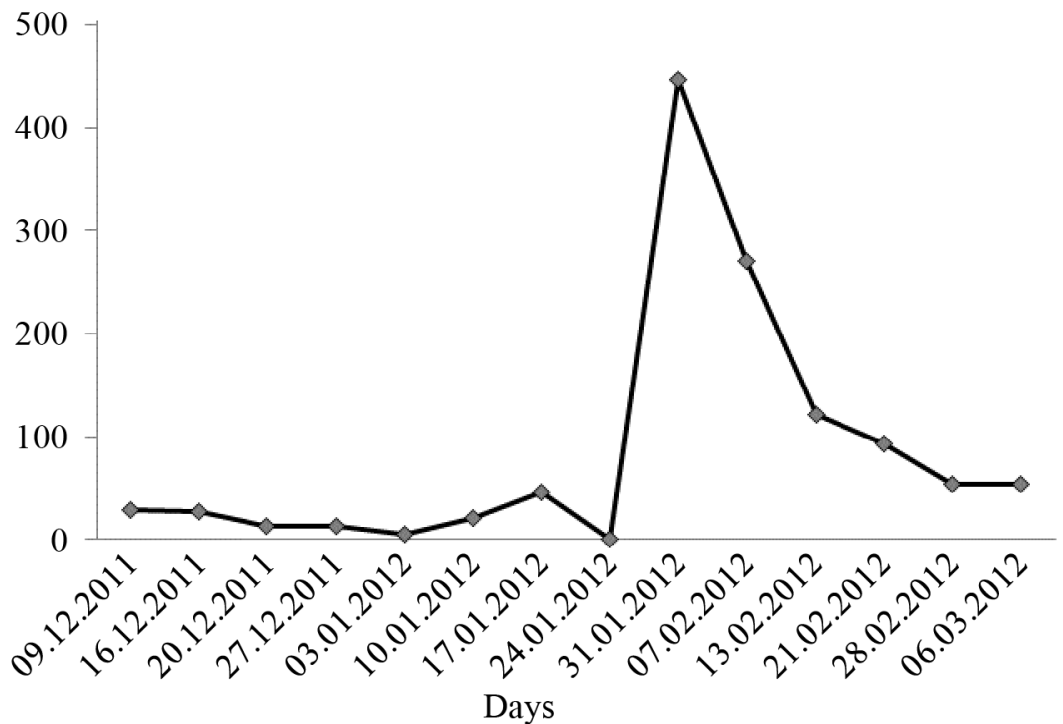

(a)

$\left[{ }^{\circ} \mathbf{C}\right]$

$[\mathbf{m m}]$
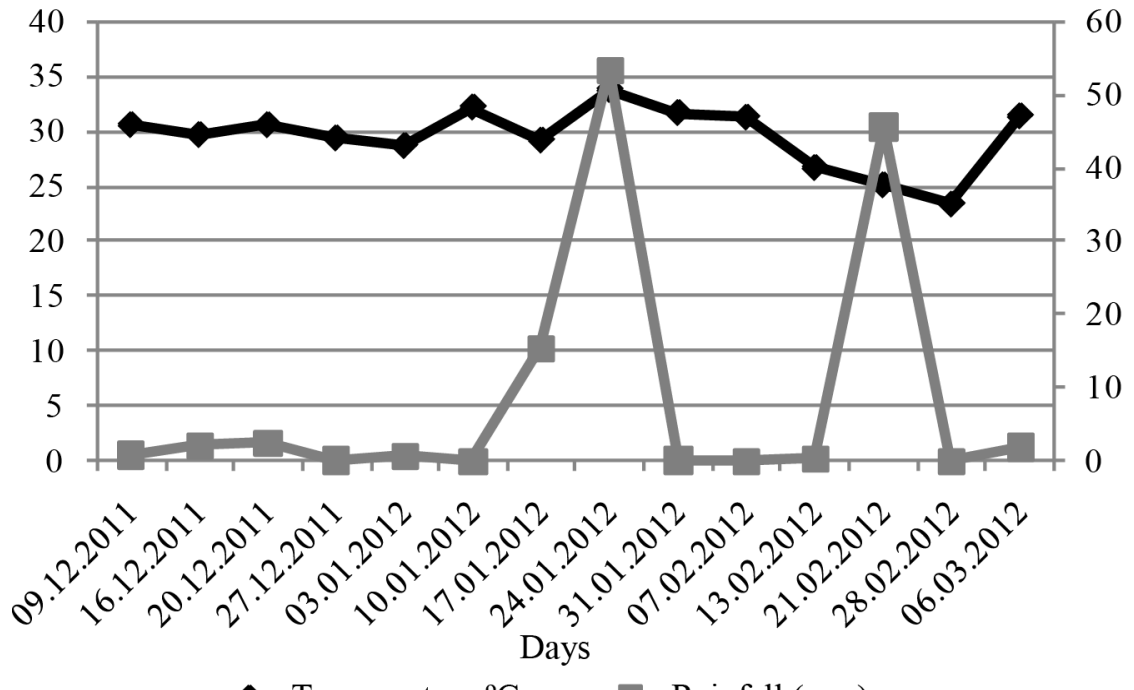

$\rightarrow$ Temperatura ${ }^{\circ} \mathrm{C} \quad-$ Rainfall $(\mathrm{mm})$

(b)

Figure 1. Population distribution of Epitrix spp. (A), temperature and rainfall (B), from December 2011 to March 2012 in the municipality of Rio Pardo (RS).

The increasing of Epitrix spp. can be also seen by the low pluviosity index and a period of temperatures higher than $31^{\circ} \mathrm{C}$. These conditions are very favorable to the development of this species, and this inference is corroborated when analyzed by the Pearson's correlation: It is observed a positive relation between Epitrix density and temperature (0.11), showing that the highest is the temperature, more increasing on the populational density is expected. The temperature is one of the most influential environmental factors, being like a regulator, once the insects cannot regulate their temperature themselves [24]. 
Table 1. Distribution of the population of Epitrix spp. in the different lines and sampling points, from December 2011 to March 2012.

\begin{tabular}{|c|c|c|c|c|c|c|c|c|c|c|c|c|c|}
\hline \multirow{2}{*}{$\begin{array}{l}\text { Collection } \\
\text { Dates }\end{array}$} & \multicolumn{4}{|c|}{ Line 01} & \multicolumn{4}{|c|}{ Line 02} & \multicolumn{4}{|c|}{ Line 03} & \multirow[b]{2}{*}{ Total } \\
\hline & $\mathrm{O}$ & B & I & $\mathrm{C}$ & $\mathrm{O}$ & B & I & $\mathrm{C}$ & $\mathrm{O}$ & B & I & $\mathrm{C}$ & \\
\hline 09.12 .11 & 4 & 14 & 5 & 2 & 2 & 0 & 3 & 0 & 1 & 1 & 1 & 0 & 33 \\
\hline 16.12 .11 & 2 & 8 & 3 & 4 & 1 & 2 & 0 & 2 & 2 & 0 & 3 & 0 & 27 \\
\hline 20.12 .11 & 0 & 1 & 5 & 0 & 1 & 1 & 0 & 0 & 1 & 1 & 0 & 3 & 13 \\
\hline 27.12 .11 & 1 & 1 & 1 & 4 & 0 & 2 & 1 & 0 & 0 & 1 & 3 & 0 & 14 \\
\hline 03.12 .11 & 3 & 5 & 0 & 4 & 6 & 4 & 4 & 0 & 0 & 0 & 2 & 0 & 28 \\
\hline 10.01 .12 & 0 & 18 & 12 & 7 & 3 & 11 & 3 & 0 & 0 & 0 & 2 & 5 & 61 \\
\hline 17.01 .12 & 4 & 13 & 13 & 6 & 4 & 17 & 15 & 3 & 0 & 3 & 10 & 4 & 92 \\
\hline 24.01 .12 & 6 & 23 & 38 & 3 & 8 & 43 & 10 & 4 & 1 & 2 & 10 & 8 & 156 \\
\hline 31.01 .12 & 100 & 58 & 54 & 37 & 27 & 77 & 45 & 24 & 2 & 7 & 8 & 23 & 457 \\
\hline 07.02 .12 & 7 & 43 & 58 & 8 & 7 & 103 & 3 & 16 & 0 & 3 & 8 & 20 & 276 \\
\hline 13.02 .12 & 2 & 8 & 40 & 1 & 2 & 51 & 16 & 11 & 1 & 3 & 12 & 1 & 148 \\
\hline 21.02 .12 & 9 & 7 & 22 & 0 & 0 & 30 & 26 & 4 & 0 & 1 & 10 & 4 & 113 \\
\hline 28.02 .12 & 4 & 3 & 12 & 13 & 1 & 2 & 11 & 19 & 1 & 4 & 7 & 3 & 80 \\
\hline 06.03 .12 & 0 & 11 & 17 & 1 & 0 & 11 & 14 & 17 & 0 & 6 & 2 & 7 & 86 \\
\hline Total & 142 & 213 & 280 & 90 & 62 & 349 & 151 & 100 & 9 & 32 & 78 & 78 & 1584 \\
\hline
\end{tabular}

About the relations between the populational density and pluviosity, it is observed a negative influence $(-0.18)$. As seen, therefore, an increase of precipitation means a decrease in the Epitrix populations in the tobacco fields. This data corroborates the inferences of Ohashi and Urdampileta [2], which observed that Epirtix individuals have better spreading in dry periods. Another study like Cividanes and Cividanes [25] remarks that among the weather factors evaluated for them, the pluvial precipitation was the most influencer on the occurrence of carabid coleopterans, observing about $64 \%$ of variation on density of the populations sampled.

After the tobacco planting, the adults of Epitrix spp. make a migration from the border to the plantation. This is well observed when the samplings are analyzed from the fifth week to the end (Table 1). In this case, after the eclosion of flea beetles larvae, when the individuals attack the plant roots, the adults start to cause damages to the foliar area [2]. In the present study, we also observed a similar behavior, where the adult population peak of Epitrix manifested between late January and early February, characterizing as a late pest of tobacco crop.

There is a significant difference between the Lines 01 and 03, and a non-significant one when compared the Lines 01 and 02 and Lines 02 and 03 . This notable discrepancy can be explained by the presence of adjacent vegetation, which influences the activity of the sampled specimens of Epitrix spp., since the greatest abundance was observed in Line 01 with $46 \%$ of the individuals col- 
lected, followed by Line 02 with $42 \%$. As Cuthberson [3] mentions, this coleopteran presents a food preference by some solanaceans, as well as fabaceans and chenopodiaceans. Species of these families were composes of the border vegetation at the Lines 01 and 02 , presenting a greater floristical abundance than Line 03 , where the predominant phytophysionomy were grasslands.

Regarding the distribution of Epitrix spp. in the collection points (Table 2), it was verified that the Border point differed statistically from the Outside point. It has not occurred with the other two points sampled (Figure 2). It was also observed that the points of greatest abundance were the Border of the plantation, with $37.5 \%$ of specimens collected, followed by the Inside point with $32.19 \%$ (Figure 3). This may have occurred because females lay the eggs more at the border of the crop, so when Epitrix spp. individuals are born, they are more collected in this area.

When monitored the populational development of Epitrix spp., Pérez-Otero et al. [26] remark that the best way to control this plague, is preventing the female entrance in the plantation for egg deposition in December, as well as the observing of the adjacent vegetation, evaluating their presence or absence. Looking at the results of this study, the inference is well corroborated, when it is possible to see the first population peak of Epitrix at the end of January, a month and a half later (period of the total life cycle) that females found in the plants adjacent to the crop, oviposited the tobacco and thus initiating a new infestation in the crop.

Table 2. Mean number of Epitrix spp. collected in the sampling lines.

\begin{tabular}{ccc}
\hline Line 01 & Line 02 & Line 03 \\
\hline $51.78 \pm 63.56 \mathrm{a}$ & $47.64 \pm 51.78 \mathrm{ac}$ & $14.07 \pm 11.13 \mathrm{bc}$ \\
\hline
\end{tabular}

The averages followed by the same letter on the line do not differ from each other by the Kruskal-Wallis test $<0.05)$. The standard deviation was calculated using BioEstat 5.0.

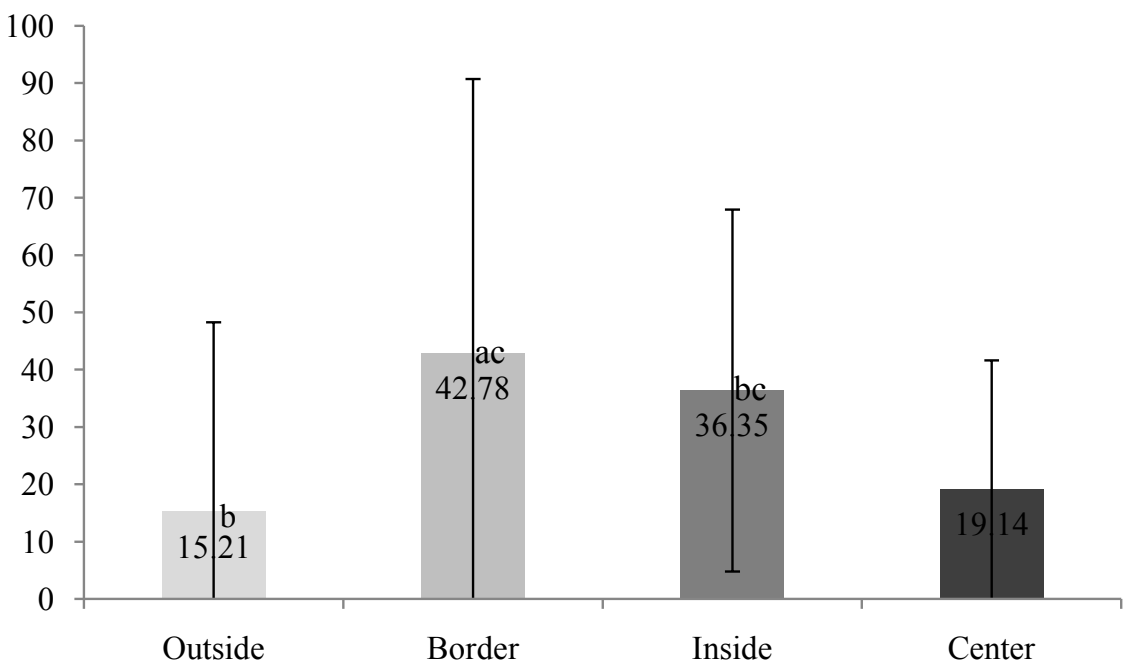

Figure 2. Mean number of Epitrix spp. sampling points. The averages followed by the same letter on the line do not differ from each other by the Kruskal-Wallis test $<0.05$ ). 


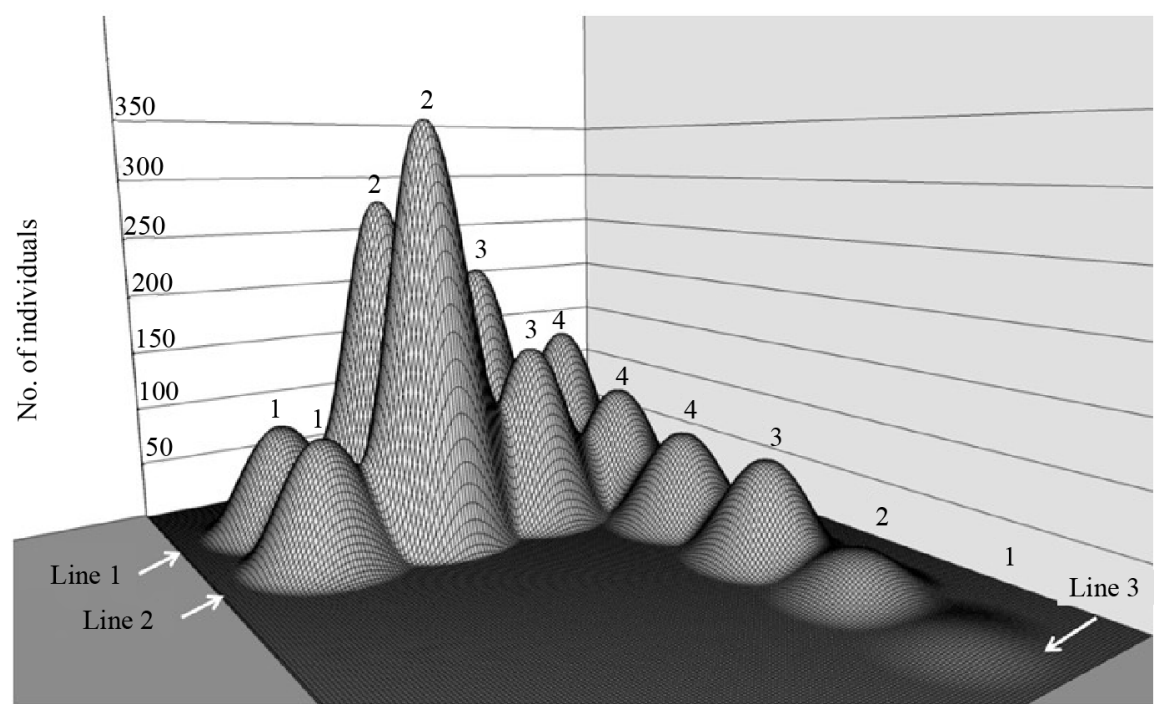

Figure 3. Spatial distribution of Epitrix spp. in the sampling lines arranged in the field of organic tobacco, from December 2011 to March 2012.

Another way of control mentioned by Pérez-Otero et al. [26] is the crop rotation of non-Solanaceae plants and the utter elimination of tobacco cropping rests and of weeds, hosts of Epitrix spp. which are close to the crop.

\section{Conclusions}

Population fluctuation and spatial distribution show a large concentration of beetles on the fleas within and at the border of the crop, as well as a higher incidence in the periods of the first harvest of tobacco leaves. It was observed that in lines 1 and 2, the largest amount of individuals was sampled. This is because the adjacent vegetation composed of trees and shrubs is possibly an Epitrix spp. refuge area when there is no tobacco in the crop. Research into which plants provide resources and shelter becomes necessary.

Through the mapping of spatial distribution and population fluctuation with the methodology adopted in the present study, it was possible to observe the influence of biotic and abiotic factors on the occurrence of the pest, as well as to determine the importance of the vegetation surrounding the crop, phenology and attack of Epitrix spp. The results presented here can aid in the planning of the most indicated methods in the detection and control of the pest, for the correct application of a rational and sustainable management, avoiding economic losses. However, Epitrix taxonomy studies are still needed, especially in relation to species that occur in tobacco growing.

\section{Acknowledgements}

The authors thank JTI-Japan Tobacco International to the conceding of study sites, as well as MSc. Jonas Moraes by the taxonomy orientations and the BSc. José Ricardo Assmann Lemes for the statistical help. Furthermore, the authors are grateful to UNISC for the financial support. 


\section{References}

[1] Doeberl, M. (2000) Contribution to the Knowledge of the Genus Epitrix Foudras, 1860 in the Palearctic Region (Coleoptera: Chrysomelidae: Alticinae). Mitteilungen des Internationaler Entomologischer Verein, 25, 1-23.

[2] Ohashi, D.V. and Urdampilleta, J.D. (2003) Interaction between Harmful and Beneficial Insects in Tobacco Cultivation in Misiones, Argentina. Revista de Investigaciones Agropecuarias, 32, 113-124.

[3] Cuthbertson, A.G.S. (2015) Chemical and Ecological Control Methods for Epitrix spp. Global Journal Environmental Science Management, 1, 95-97.

[4] Boavida, C. (2010) Epitrix of Potato: A New Exotic Pest in Portugal. Revista da Associação Portuguesa de horticultura, 4, 1-4.

http://www.iniav.pt/fotos/editor2/epitrix_similaris_gentner_epitrix_da_batateira.p df

[5] Guedes, J.C. and Sulzbach, F. (2006) Guide to Integrated Pest Management and Identification. Orium, Santa Maria.

[6] Altieri, M.A. (1999) The Ecological Role of Biodiversity in Agroecosystems. Agriculture, Ecosystems and Environment, 74, 19-31. https://doi.org/10.1016/S0167-8809(99)00028-6

[7] Kuppert, G. and Thomas, R. (2010) Organic Tobacco Production. A Publication of ATTRA-National Sustainable Agriculture Information Service, 1-8.

[8] Landoni, J.H. (1990) Nicotiana tabacum L. http://www.inchem.org/documents/pims/plant/nicotab.htm

[9] Carvalho, C., Kist, B.B., dos Santos, C.E., Reetz, E.R. and Drum, M. (2014) Brazilian Tobacco Yearbook 2014. Editora Gazeta Santa Cruz, Santa Cruz do Sul.

[10] Specht, A., Guedes, J.V.C., Sulzbach, F. and Vogt, T.G. (2006) Occurrence of Rachiplusia nu (Guenée) (Lepidoptera: Noctuidae) in tobacco (Nicotiana tabacum L.) in Rio Grande do Sul. Neotropical Entomology, 35, 705-706. https://doi.org/10.1590/S1519-566X2006000500020

[11] Nicholls, C.I. and Altieri, M.A. (2007) Projection and Implementation of a Habitat Management Strategy to Improve the Biological Control of Pests in Agroecosystems. In: Nicholls, C.I., Altieri, M.A. and Ponti, L., Eds., Biological Control of Pests through the Management of Agroecosystems, Brasília, Ministério do Desenvolvimento Agrário, Departamento de Assistência Técnica e Extensão Rural, 33.

[12] Altieri, M.A. and Letourneau, D.K. (1982) Vegetation Management and Biological Control in Agroecosystems. Crop Protection, 1, 405-430. https://doi.org/10.1016/0261-2194(82)90023-0

[13] Moraes, J. and Köhler, A. (2012) Population Fluctuation and Spatial Distribution of Diabrotica speciosa Gemar, 1824 (Coleoptera: Chrysomelidae) on Organic Tobacco Cultivation. Bioikos, Campinas.

[14] Leifheit, O.J. (1978) Introduction to the Study of the Environment of Santa Cruz do Sul. Editora Movimento, Porto Alegre.

[15] Hoppe, M. (2005) Pluviometry in Santa Cruz do Sul. Bulletin No. 11/Year VII.

[16] Diedrich, V.L., Ferreira, E.R. and Eckhardt, R.R. (2007) Spatialization of Estimates of the Maximum, Average and Minimum Annual Temperatures for the Vale do Taquari-RS, Brazil, Using the Linear Regression Method. http://marte.sid.inpe.br/col/dpi.inpe.br/sbsr@80/2006/11.15.21.56/doc/153-159.pdf

[17] Ruoso, D. (2007) The Climate of Santa Cruz do Sul-RS and the Climatic Perception 
of the Urban Population. Masters Dissertation, Federal University of Santa Maria, Santa Maria.

[18] Rafael, J.A., Melo, G.A.R., de Carvalho, C.J.B., Casari, A.S. and Constantino, R. (2012) Insects of Brazil: Diversity and Taxonomy. Holos Editora, Ribeirão Preto.

[19] Bryant, G.E. (1940) A New Species of Injurious Phytophaga (Coleopt.) from the Argentine Republic. Proceeding Royal Entomological Society of London, 9, 54. https://doi.org/10.1111/j.1365-3113.1940.tb00342.x

[20] Costa Lima, A.M. (1953) Insects of Brazil: 8th Volume: Coleoptera. National School of Agronomy, Federal Rural University of Rio de Janeiro, Rio de Janeiro.

[21] Bechyné, J. (1955) Journey of Mr. G. Frey in South America: Alticidae (Col., Phyt.). Entomoloogische Arbeiten aus dem Museum G. Frey. Tutzingen bei München, 6, 5-74.

[22] Ayres, M., Ayres Júnior, M., Ayres, D.L. and Santos, A.A. (2007) BIOESTAT-Statistical Applications in the Areas of Bio-Medical Sciences.

http://www.mamiraua.org.br/pt-br/downloads/programas

[23] Hammer, Ø., Harper, D.A.T. and Ryan, P.D. (2001) PAST: Paleontological Statistics Software Package for Education and Data Analysis. http://nhm2.uio.no/norlex/past/download.html

[24] Rodrigues, W.C. (2004) Factors Influencing the Development of Insects. Info Insetos, 4, 1-4.

[25] Cividanes, F.J. and Cividanes, T.M.S. (2008) Population Fluctuation and Fauna Analysis of Carabidae and Staphylinidae (Coleoptera) in Jaboticabal, São Paulo. Arquivos do Instituto Biológico, 75, 449-456.

[26] Pérez-Otero, R., Nicolás, R. and Mansilla, P. (2010) Epitrix similaris Gentner Potato pullet Fitopatolóxica do Areeiro Station. Deputación de Pontevedra, EFA 54/10. http://www.juntadeandalucia.es/agriculturaypesca/portal/export/sites/default/comu n/galerias/galeriaDescargas/cap/agricultura-ganaderia/agricultura/Sanidad-Vegetal/ Epitrix_similaris.pdf 